\title{
O MINISTÉRIO PÚBLICO DO TRABALHO NA PROTEÇÃO DO DIREITO DO TRABALHO
}

\author{
Rodrigo de Lacerda Carelli*
}

\begin{abstract}
O Ministério Público do Trabalho, instituição antes subalterna no sistema protetivo trabalhista, com a refundação do "parquet”, a partir da década de 1980, ganha importância na representação funcional dos trabalhadores, na tutela dos direitos fundamentais no trabalho. Assim, o texto demonstra que, no momento de crise do Direito do Trabalho e de suas instituições, o Ministério Público do Trabalho agasalha o papel de defensor da sociedade e atua no resguardo do Direito do Trabalho, reforçando-o com o argumento dos direitos humanos. Ao final, restam fortalecidos tanto a instituição quanto o ramo do Direito que busca proteger.

Palavras-Chave: Ministério Público do Trabalho, direito do trabalho, representação funcional, direitos humanos, trabalho.
\end{abstract}

\section{INTRODUÇÃO}

O renascimento do Ministério Público do Trabalho - instituição até então subalterna e com importância reduzida no sistema nacional de proteção trabalhista -, a partir das mudanças ocorridas na década de 1980, que culminaram com a Constituição de 1988, foi fruto de sua transformação em um órgão estatal, sem qualquer paralelo em outros países, com fortes instrumentos para a tutela coletiva dos trabalhadores, sendo esse um fenômeno que merece ser devidamente estudado.

O interesse na questão cresce pelo fato de coincidir esse fortalecimento do Ministério Público do Trabalho com o momento de crise por que passa o Direito do Trabalho, no qual os sindicatos parecem não ter mais forças para reagir diante da classe patronal, lutando apenas pela manutenção dos postos de trabalho, quando não

\footnotetext{
*Doutor em Ciências Sociais. Procurador do Ministério Público do Trabalho no Rio de Janeiro. Av. Churchill, n. 94, 8 andar, Castelo. Cep: 20020-050. Rio de Janeiro - Rio de Janeiro - Brasil. rodrigolcarelli@gmail.com
}

participam do enfraquecimento do Direito do Trabalho pela flexibilização (rectius: redução) das normas estatais em acordos e convenções coletivas. Nesse panorama, passam os sindicatos a procurar o Ministério Público do Trabalho para a defesa dos direitos sociais dos trabalhadores, atribuição que antes realizavam com os instrumentos tradicionais de atuação sindical.

Esse fenômeno não pode ser analisado de forma isolada, pois não somente o "parquet" balhista é revolucionado, mas o Ministério Público Brasileiro passa por uma transformação, deixando de ser defensor do Estado e do governo para ser o defensor da sociedade, representando-a na defesa dos direitos sociais e indisponíveis e no resguardo da cidadania.

Há, assim, um aparente paradoxo a ser resolvido: ao mesmo tempo em que ocorre a crise da regulação estatal do Direito do Trabalho e dos sindicatos, cresce a participação do Ministério Público do Trabalho na garantia dos direitos sociais dos trabalhadores. Ao lado desse fenô${ }^{1}$ Expressão de origem francesa pela qual usualmente se designa a Instituição Ministério Público, utilizada como sinônimo. 
meno nacional, há um reforço, na esfera internacional, do discurso de valorização dos direitos humanos que não pode ser olvidado. Pelo contrário, há que se observar se esse aspecto auxilia na resposta aos questionamentos surgidos.

Uma vez sufocados por uma estrutura legislativa que, no curso da história, só fez aprofundar o fosso entre os sindicatos e seus representados e desestimulados a negociar ou lutar por melhores condições de trabalho ou mesmo manter as atuais - causadas pela fragmentação da classe trabalhadora e pela globalização da produção e das crises do capital -, os sindicatos encontram, nesse novo Ministério Público, em seu ramo trabalhista, surgido após a Constituição de 1988 e legislação complementar, um instrumento e um aliado para a garantia de direitos fundamentais, consequentemente para a busca de cidadania para os trabalhadores. O Ministério Público do Trabalho, por sua vez, abraça o papel de defensor da sociedade e garantidor suplementar dos direitos dos trabalhadores, diante do Estado, dos empregadores e até mesmo dos próprios sindicatos.

Os sindicatos estão fragmentados e, às vezes, impedidos de representar seus trabalhadores. O Direito do Trabalho e a sua regulação pelo Estado encontram-se em crise, sendo voz corrente o clamor por reformas, tanto no Direito Individual do Trabalho quanto no Direito Coletivo do Trabalho. Ao mesmo tempo em que isso ocorre, em aparente paradoxo, surge o Novo Ministério Público, e, como um de seus ramos, o Ministério Público do Trabalho, utilizado pelos trabalhadores e pelos sindicatos como instrumento de defesa dos direitos de cidadania no trabalho.

Assim, a partir desse quadro, aparecem várias questões: como surge esse Ministério Público defensor dos direitos do trabalho? Qual o seu papel? O que leva os sindicatos a buscar esse novo órgão estatal? O que busca o Ministério Público do Trabalho? Qual sua relação com a cidadania no trabalho? E, sobretudo, o espaço em que atua o "parquet" trabalhista é o mesmo dos sindicatos ou da fiscalização trabalhista?

O presente trabalho trata a questão no âm- bito do "dever ser", ou seja, no campo normativo, não pretendendo traçar um panorama da atuação da instituição com um todo. Evidentemente, o Ministério Público do Trabalho, como toda instituição, ainda mais estatal, não é monolítica, sendo sua atuação muitas vezes díspar em termos de grau de atuação e percepção de seu papel. Essa diferença de formas de atuar é potencializada, inclusive, pela independência funcional dos membros do Ministério Público. Assim, a pretensão deste trabalho é demonstrar, com base na Constituição da República e no posicionamento do Ministério Público do Trabalho perante as demais instituições, qual o seu devido campo de atuação.

\section{A DEFESA DO DIREITO DO TRABALHO PELO MINISTÉRIO}

O que realmente está a acontecer é que os sindicatos não estão se fazendo substituir pelo Ministério Público do Trabalho, mas sim aproveitando a Instituição moldada na Constituição de 1988, como aliada para a garantia dos direitos de cidadania dos trabalhadores. Esse novo Ministério Público, que busca ainda sua identidade, aceita a sua nova função de defesa da Ordem Jurídica Justa, do Regime Democrático e da Cidadania do indivíduo e da coletividade trabalhadora, atuando a favor, e, às vezes, até contra os interesses dos sindicatos, sempre na garantia das liberdades individuais e coletivas do trabalhador.

O aparente paradoxo seria desfeito: a busca de um órgão estatal, mas não governamental, que tem por missão a defesa da sociedade e da cidadania, faz-se justamente pela necessidade de uma forte estrutura para a defesa dos direitos humanos no mundo do trabalho.

O Direito do Trabalho nasce em momento ímpar da história da civilização, fruto direto da alta exploração dos trabalhadores, e como meio de sustentação do status quo, diante das ameaças mais diretas à propriedade privada. Daí sua "ambivalência", ressaltada pelos estudiosos. Não há de se negar, por outro lado, que as novas 
ideias surgidas na evolução da sociedade democrática também tiveram um papel decisivo na gestação e posterior aprofundamento teórico desse novo tipo de ramo do Direito.

Esse Direito de novo tipo tem como terreno fértil as democracias existentes a partir do século $\mathrm{XX}$, como demonstra o movimento de Constitucionalização dos Direitos Sociais, que somente aconteceu em países com processo ou projeto democrático. Esse novo tipo de Direito encontra guarida nos documentos internacionais de proteção aos Direitos Humanos, sendo impossível seu resguardo sem a racionalidade própria de viés impositivo e protetor, seja pela via estatal, seja pela forma de negociação coletiva.

Então, pode-se dizer que o Direito do Trabalho tem atualmente o seu fundamento nos Direitos Humanos, na imprescindibilidade do seu mote básico, o Princípio da Proteção, para a garantia do seu objetivo principal, a defesa da Dignidade da Pessoa Humana do ser trabalhador, ultrapassando-se, assim, a questão da ambivalência (conquista e concessão).

Não se olvide que essa condição de imprescindibilidade pode ser negada pelos detentores do meio de produção, que vão tentar (e muitas vezes conseguir) escapar da rede protetora do Direito do Trabalho, ou negar vigência a direitos conquistados. Também não é de se esquecer que, em momentos econômicos e políticos favoráveis aos capitalistas, a pressão pela redução da proteção trabalhista será exercida com mais eficácia e incisividade, e que a resistência dos trabalhadores poderá ser insuficiente para a manutenção dos direitos. A negativa de vigência e de legitimidade do Direito do Trabalho é própria da mentalidade capitalista, e a sua fuga, como acontece quando o empresário realiza evasão de impostos ou tenta escapar de entraves burocráticos estatais, pode ser considerada como normal e esperada.

Para resguardo do Direito do Trabalho, foi criado o sistema de proteção laboral, ${ }^{2}$ do qual

${ }^{2}$ Conjunto de institutos e instituições que têm como objetivo impelir os empregadores ao cumprimento da legislação protetiva trabalhista. fazem parte, além dos sindicatos dos trabalhadores, a Inspeção do Trabalho, a Justiça do Trabalho e, entrando recentemente no rol de instituições, o Ministério Público do Trabalho. Com base nos estudos de Cardoso e Lage (2007), demonstra-se a importância da atuação dessas instituições no sistema de proteção para a efetividade dos direitos trabalhistas. Sem elas, ou com a sua atuação ineficiente, incentiva-se o capitalista a deslegitimar o Direito do Trabalho, negando o seu cumprimento. Quanto mais dura for a punição e mais frequente for a fiscalização da observância de suas normas, mais efetivo será o Direito do Trabalho (Cardoso; Lage, 2007).

E o "parquet" laboral vem se colocar para valer como uma das instituições do sistema protetivo trabalhista a partir do novo perfil do Ministério Público. O “novo” Ministério Público se desfaz da função de proteção de interesses estatais e governamentais e passa a se concentrar, tão somente, na defesa da Sociedade, consubstanciada no interesse público primário. Além disso, o faz com total independência diante dos poderes clássicos da República, sendo que a conjunção desses dois elementos é essencial para a caracterização de ineditismo do "parquet" brasileiro frente aos similares alienígenas.

Assim, legitimado pela função constitucional de defesa dos direitos fundamentais da sociedade, o Ministério Público do Trabalho assume essa representação funcional da sociedade e passa a defender os trabalhadores imediatamente, e, de forma mediata (e finalística), o próprio Direito do Trabalho, com vistas à garantia da sua função primordial: o resguardo da dignidade da pessoa humana.

\section{ADEFESA DO DIREITO DO TRABALHO PELO VIÉS DOS DIREITOS HUMANOS}

Como se percebe nas argumentações do Ministério Público do Trabalho, os direitos fundamentais aparecem sempre nas fundamentações, mesmo com a existência de normas ex- 
pressas, que já dariam, por si só, guarida à tutela pretendida pelo Ministério Público do Trabalho. Seja quando são utilizados como princípio legitimador da norma, seja quando acionados como norma, os direitos fundamentais aparecem como ponto de partida, ou norte, para a atuação do "parquet” laboral.

Quando ausentes normas específicas para a proteção do bem jurídico que se pretende tutelar, pretende o "parquet” a correção da injustiça pela criação de obrigação inexistente em lei, pela aplicação direta de princípios de Direitos Humanos. Na inércia do legislador, busca corrigir a falha do sistema legislativo, ao "criar" a norma a partir do princípio da dignidade da pessoa humana e do direito social à moradia. Nesse caso, a fiscalização do trabalho nada poderia fazer, e os sindicatos poderiam tentar criar normas autônomas para o caso, por meio de negociação coletiva, o que demandaria a concordância da representação dos empregadores, não surgindo da aplicação de princípios, mas do resultado do confronto de forças entre capital e trabalho. Aqui defende os direitos fundamentais substanciais, pretendendo o resguardo direto dos princípios como direitos a serem usufruídos pelos trabalhadores.

Quando defende a aplicação de norma coletiva, negociada pelos atores sociais coletivos, o Ministério Público justifica essa atuação com o argumento de estar protegendo os direitos fundamentais, demonstrando, assim, sua legitimidade. A defesa, assim, em última instância, é do próprio Direito do Trabalho e de suas instituições, como indispensáveis para a tutela da pessoa humana. Aqui se abre questão interessante, similar àquela discutida por Paoli e French: a repetição de normas jurídicas em outros instrumentos e níveis, com o objetivo de se obter a efetividade do direito defendido (Paoli, 1988; French, 2004). Como observou Paoli, a repetição, em acordos e convenções coletivas, de dispositivos já existentes na lei serviu como legitimadora das pretensões dos trabalhadores de eficácia do Direito do Trabalho (Paoli, 1988). Podemos, então, concluir que o mesmo ocorre na atuação do Ministério
Público do Trabalho quando, ao pretender a aplicação de normas legais ou convencionais, vai buscar nos Direitos Humanos a legitimação da pretensão de vigência do Direito do Trabalho. Os Direitos Humanos agora fazem o mesmo papel que vislumbrou Paoli: dar maior legitimidade ao Direito do Trabalho, possibilitando sua maior eficácia. Inverte-se, então, a previsão de Radbruch, realizada no início do século XX, de que “a missão do novo Direito Operário se estabelece em conceder validade aos Direitos Humanos do operário” (Radbruch, 1930, p.115): são os Direitos Humanos que concedem (ou reafirmam a) validade ao Direito do Trabalho. Segundo Ferrajoli, os Direitos Humanos foram estabelecidos historicamente nos diplomas constitucionais como resultado das lutas ou revoluções que vinham em decorrência de alguma opressão ou discriminação, sendo conquistados como limitações de poderes e em defesa dos sujeitos mais fracos contra a lei do mais forte que regia anteriormente na ausência dos direitos fundamentais (2008, p.51). Entre esses "mais fortes" que regiam as relações inclui o autor "igrejas, soberanos, maiorias, aparatos policiais, judiciais, empresários, potestades paternas ou maritais”. Assim, os Direitos Humanos, vindo a demonstrar a injustiça da lei do mais forte na relação de trabalho, submete o poder do empregador ao Direito do Trabalho.

E o princípio da dignidade da pessoa humana, presente não somente nos tratados e declarações internacionais, mas também como mola-mestra no sistema constitucional brasileiro, aparece como base em quase toda a atuação do Ministério Público do Trabalho.

Aqui surge outra característica da representação funcional exercida pelo "parquet” trabalhista: a defesa dos direitos fundamentais, independentemente da existência de lei expressa no sentido da proteção pretendida, com a mera utilização de princípios aos quais se dá concretude em casos específicos, por meio da criação de novas normas. 


\section{O MINISTÉRIO PÚBLICO DO TRABALHO E SEUS CRÍTICOS}

A atuação do Ministério Público do Trabalho rebate algumas das críticas apresentadas à judicialização. Como aquela realizada por Sorj (2004), que afirma que

... a judicialização do social é um processo duplo de fragilização do Direito: no plano institucional, já que remete toda nova legislação a seus fundamentos constitucionais, ou, ainda, aos direitos humanos; e no plano das relações cotidianas, pela contratualização crescente das relações sociais, em particular as de trabalho, mas também das familiares e dos sistemas de previdência, educação e saúde (p.62).

Aduz que "a judicialização das relações sociais prejudica em particular os setores mais frágeis, distantes do acesso ao sistema judiciário". Explica seu argumento que

... a contratualização das relações sociais permite, em nome da autonomia das partes, a reintrodução de relações de poder e de opressão no mundo do trabalho, enquanto a constitucionalização leva ao desengajamento do cidadão face às decisões e compromissos políticos assumidos por governos democraticamente eleitos (ênfase no original).

Ora, a análise da atuação do Ministério Público do Trabalho indica justamente o contrário. Inicialmente, o autor citado analisa o Poder Judiciário pelo viés do processo individual liberal, já ultrapassado, não percebendo o processo de coletivização do acesso à Justiça do qual faz parte o "parquet" trabalhista. Assim, ao contrário do alegado por Sorj, a possibilidade de utilização do Ministério Público como fórum de busca de direitos abre aos setores menos organizados e frágeis uma via de acesso à Justiça em seu sentido substancial e até mesmo formal. A segunda crítica também não procede. Como vimos, a utilização dos direitos humanos para justificar e fundamentar o direito legislado infraconstitucional não retira sua legitimidade e obrigatoriedade, mas sim, ao revés, concede-lhe mais força e eficácia, removendo possíveis empecilhos, até mesmo ide- ológicos, à sua aplicação e efetividade. Ao contrário da proclamada individualização, o que percebemos é a busca da efetivação do Direito como um todo e o fortalecimento das instâncias coletivas de proteção.

O eixo analítico mais conservador quanto à judicialização das relações sociais teve suas críticas resumidas por Werneck Vianna et al como sendo

perda da liberdade, "ao gozo passivo de direitos", "à privatização da cidadania”, ao paternalismo estatal, tudo isso na caracterização de Habermas, e de "clericalização da burocracia", "justiça de salvação", e a redução dos cidadãos ao estatuto de indivíduos-clientes de um Estado providencial (Werneck Vianna et al, 1999, p. 23-24).

Podemos afastar algumas dessas críticas. A busca de proteção à contratação coletiva pretende a afirmação da liberdade dos trabalhadores em sua organização coletiva. Assim, em última análise, o que se realiza é a garantia de os trabalhadores lutarem ativamente pelos direitos dentro de sua organização representativa, em um "gozo ativo de direitos", e também um aumento de liberdade coletiva. Quando o Ministério Público, por exemplo, pretende exigir a negociação prévia da empresa com a entidade sindical, antes de uma dispensa em massa, essa atitude é exemplar no sentido de utilização do lócus público jurídico não como uma "Justiça de Salvação", mas sim instância garantidora de condições mínimas de diálogo democrático dentro do espaço privado.

Ao lado dos direitos fundamentais substanciais, defende também o Ministério Público do Trabalho os direitos fundamentais procedimentais, para a garantia da regra democrática no âmbito privado. Assim, por exemplo, quando defende a concessão de moradias dignas, a proibição de intermediação de mão de obra, ou quando pretende a proibição da função de degustador de cigarros, está o "parquet" defendendo os direitos fundamentais substanciais. Por outro lado, ao tentar garantir o devido processo legal dentro de uma empresa, ou a 
obrigatoriedade da negociação coletiva, a defesa aí é de direitos fundamentais procedimentais. Assim, perfaz-se a dupla defesa inscrita no art.127 da Constituição Federal: a defesa do Regime Democrático, garantindo os direitos fundamentais procedimentais, e a tutela dos direitos sociais e individuais indisponíveis, ou seja, a proteção aos direitos fundamentais substanciais.

A atuação do "parquet" também traz à baila a aplicação dos princípios como normas, e não como meros norteadores da interpretação e aplicação da lei, seguindo a teoria mais moderna do Direito, própria dos regimes democráticos. É o que nos traz Cappelletti, aduzindo que

... apenas em sistemas democráticos de governo os direitos do homem têm a chance de serem respeitados. Contudo, o inverso também se mostra verdadeiro: a democracia não pode sobreviver em um sistema em que fiquem desprotegidos os direitos e as liberdades fundamentais. (1993, p.106)

E, como explica Badinter, houve uma vontade política em todas as democracias surgidas de regimes totalitários ou ditatoriais de se edificarem defesas judiciárias fortes para garantir as liberdades individuais ou públicas, citando exemplos da Alemanha e da Itália e do leste europeu (Badinter; Breyer, 2003, p.47-48). A garantia dos direitos fundamentais, dessa forma, estaria inserida no próprio contexto democrático, fazendo parte inseparável das democracias modernas. Dieter Grimm, concordando com a proposição, acrescenta que

... os direitos fundamentais não dão somente uma proteção contra o Estado, mas igualmente contra a ameaça, qualquer que ela seja, de não poder exercê-los. O exercício de direitos fundamentais exige que certos pressupostos sejam satisfeitos. Se esses não são garantidos, a existência de um direito individual não vale grande coisa (Badinter; Breyer, 2003, p.56).

Assim, a tutela dos direitos e liberdades fundamentais dos trabalhadores realizada pelo Ministério Público do Trabalho está inserida em um sentido de proteção da democracia, cumprindo umas das incumbências do "novo" Ministério
Público impostas no art.127 da Constituição Federal: a proteção do Regime Democrático. ${ }^{3}$

De fato, o Ministério Público do Trabalho pretende a refundação das relações entre empregado e empregador, com a intenção de transformar um ambiente normalmente despótico em lócus de práticas e relações democráticas. Não somente o público tem de ser democrático, mas as relações privadas devem também seguir a forma de organização da sociedade atual.

Como afirma Dworkin, a democracia majoritária só é uma de suas concepções possíveis, sendo que o que deve ser avaliado é a atuação do Poder Judiciário (e aí poderíamos incluir o Ministério Público) para conduzir a mais democracia, “... contribuindo a que sejam autenticamente realizadas as condições exigidas para o funcionamento de uma autêntica democracia." (Badinter; Breyer, 2003, p.92).

Dworkin entende que a democracia tem como pressuposto o governo justo da maioria, e que esse governo somente será justo se resguardar certas condições, que são os direitos fundamentais, necessitando, assim, de meios, como o controle de constitucionalidade e outros, para garantir que essas condições da democracia sejam cumpridas (Badinter; Breyer, 2003, p.102). Comentando as opiniões de Dworkin, Badinter (2003, p.121) aduz que a judicialização não é uma construção artificial, nem um golpe de Estado dos juízes, mas que o fenômeno se integra na evolução do conjunto da democracia contemporânea sem opor-se a ela. Ao revés, com esse fenômeno, “... a democracia 'anda' melhor ou, pelo menos, um pouco menos mal”.

Com o que concorda Cappelletti, ao entender que parece bem evidente o fato de a democracia não poder ser reduzida à simples ideia majoritária, significando também participação, tolerância e liberdade. Aduz que, ao contrário, um Poder Judiciário "ativo, dinâmico e criativo" - justamente por se afastar da regra majoritá-

Art. 127 - O Ministério Público é instituição permanente, essencial à função jurisdicional do Estado, incumbindolhe a defesa da ordem jurídica, do regime democrático e dos interesses sociais e individuais indisponíveis. 
ria, "razoavelmente independente de caprichos, talvez momentâneos, da maioria" - pode ser uma grande contribuição à democracia (1993, p.107). Seu papel, na democracia, também estaria em realizar bem a preservação do sistema de pesos e contrapesos "e também controles adequados perante os outros centros de poder (não governativos ou quase-governativos), tão típicos de nossas sociedades contemporâneas.” (p.107).

$\mathrm{E}$, dentre esses centros de poder que cita Cappelletti, por óbvio, estão as empresas, que necessitam do controle democrático. Assim, ao pretender que o devido processo legal seja observado no ambiente privado, no caso de punições ou descontos, e que os descontos salariais somente se façam a partir de um procedimento com garantia de ampla defesa ao trabalhador, está o Ministério Público do Trabalho claramente pretendendo desconstruir a ideia do despotismo fabril, abrindo à vida democrática esse centro de poder antes autoritário e até mesmo inatingível, com a criação e implementação de regras procedimentais democráticas dentro da empresa. Da mesma forma, no caso de uma demissão em massa, a tentativa de submissão de uma decisão empresarial de dispensa coletiva de trabalhadores, algo tido antes como intransponível da esfera de decisão do empregador, pretende o "parquet" flexibilizar o direito de propriedade, submetendo-o ao princípio democrático, por meio da procedimentalização da tomada de decisões na empresa (obviamente com a garantia do direito de informação ao sindicato). Nisso reside o que Cappelletti disse na transcrição apresentada anteriormente: democracia é "participação, tolerância, liberdade”.

Ferrajoli entende que, graças à introdução dos direitos fundamentais no âmbito trabalhista, a fábrica deixa de ser um lugar privado, afastando-se da ideia de mera propriedade imobiliária do empregador, convertendo-se em um espaço público, adquirindo a própria relação de trabalho uma dimensão pública, dentro da qual o trabalhador deixa de ser mercadoria e se converte em sujeito de direitos fundamentais (2008, p. 287).
E continua Ferrajoli afirmando que esse movimento de publicização do espaço fabril se deu a partir do próprio surgimento do Direito do Trabalho, com a progressiva erosão das suas originárias conotações de direito privado em favor do desenvolvimento de sua dimensão de Direito Público (p.288).

Não confunde Ferrajoli "esfera pública" com a "estatal". A diferença entre esfera pública e privada seria que a primeira tem como finalidade a garantia, por meio dos direitos fundamentais da dignidade das pessoas, e, assim, a igualdade, ou, ao menos, níveis mínimos de igualdade, enquanto a esfera privada, por sua vez, é aquela na qual, pela dinâmica de mercado e de direitos patrimoniais, leva à desigualdade. Assim, entende que a esfera pública existirá, até mesmo no âmbito privado, quando houver a incidência direta ou indireta dos direitos fundamentais (2008, p.289).

Afirma que, no caso italiano, o Estatuto dos Trabalhadores, "graças à explícita introdução na relação de trabalho da lógica dos direitos fundamentais como direitos universais e indisponíveis, o que alterou radicalmente o velho modelo de direito privado até se configurar como uma verdadeira troca de paradigma” (p. 288, tradução minha). No caso brasileiro, podemos dizer que a constitucionalização do Direito do Trabalho e, em escala bem menor, essa forma de atuação do Ministério Público do Trabalho estão buscando realizar essa transformação do espaço de trabalho em lócus de Direito.

E, concordando com Cappelletti, Ferrajoli aduz que, como ocorreu no passado, o progresso da democracia terá lugar no futuro mediante a expansão dos direitos e de suas garantias, pela extensão do Estado de Direito a um maior número de âmbitos da vida e esferas de poder, para que em todos estejam bem tutelados e satisfeitos os direitos fundamentais das pessoas (2008, p.300). Percebe-se, na atuação ministerial, a discussão da função social da propriedade e do valor do trabalho, ressaltando-os como fundamentos da nossa própria República Democrática, 
como consta do art. $1^{\circ}$ da nossa Constituição, o que está a demonstrar essa pretensão de fundação de um ambiente democrático dentro das empresas. Não se pode admitir o direito de propriedade sem o cumprimento de sua função social e a valorização do trabalho humano. Essa é a base da democracia nas relações de trabalho. É exemplar a atuação do "parquet" em casos de assédio moral, pela qual se pretende que o empregador não somente não cometa a lesão, mas que seja responsável por todo o ambiente laboral, impedindo essa prática por parte de empregados e prepostos.

A defesa do sistema coletivo, com o combate a atos antissindicais, e a defesa do disposto em convenções coletivas vêm proteger os direitos de ação coletiva, o que Supiot (2005, p.233) entende como a nota que faz do Estado Providência superior aos Estados Totalitários (e não as proteções sociais, que seriam menos tímidas nos Estados fascistas e comunistas). Para o autor (p.233), os direitos de ação coletiva, com a institucionalização dos sindicatos, da greve e da negociação coletiva, transformam relações de força em relações de direito, tendo o reconhecimento desses direitos permitido uma "hermenêutica social do direito civil", sem a qual não existiriam nem o direito do trabalho, nem a seguridade social.

Assim, ao defender a atuação sindical, está o Ministério Público do Trabalho resguardando todo o sistema trabalhista e o Direito do Trabalho, tanto em relação aos direitos substanciais quanto aos formais.

No entanto, dissocia-se a defesa de direitos dos trabalhadores realizada pelo Ministério Público daquela feita pelos sindicatos profissionais, ou pelos trabalhadores diretamente. Enquanto esses últimos defendem interesses, o "parquet" defende princípios, tendo como norte o resguardo do regime democrático, por meio da tutela dos Direitos Humanos na relação de trabalho. A tutela realizada pelo Ministério Público não é de interesses privados. Daí porque, como vimos na ocorrência do adicional de periculosidade, em alguns casos, os procuradores atuam até mesmo contrariamente ao interesse de alguns trabalhadores, com vistas à proteção do sistema trabalhista.

É de extrema importância a divisão de papéis entre os sindicatos, a Fiscalização e o Ministério Público do Trabalho. Apesar de fazerem parte do sistema protetivo trabalhista e serem imprescindíveis, como vimos, para o resguardo do Direito do Trabalho, cada um exerce um papel diferenciado, sendo o do "parquet" a tutela dos direitos fundamentais, com vistas ao resguardo do sistema democrático.

As metas escolhidas e as estratégias planejadas demonstram que o Ministério Público pretende atuar, com a defesa dos direitos fundamentais, na proteção de todo o sistema trabalhista. Assim, ao mesmo tempo em que atua diretamente na representação funcional por meio da atuação extrajudicial e judicial, pretende também defender a atuação dos outros atores, seja conclamando os sindicatos a assumirem sua função de defesa dos interesses dos trabalhadores, seja realizando a luta pela "preservação e ampliação da competência da Justiça do Trabalho", ou mesmo ajuizando ações civis públicas para a garantia da atuação sindical (como a atuação em casos de empresas que ajuízam interditos proibitórios com o fim de impedir greves).

Em outra pesquisa de que participamos, ${ }^{4}$ por meio de entrevistas realizadas com dirigentes sindicais, surgiu conclusão similar quanto à tutela pelo "parquet" dos direitos fundamentais, com papel diferenciado das demais instituições. Naquela pesquisa, os entrevistados demonstraram deixar ao Ministério Público papéis como o combate às terceirizações ilícitas e o resguardo do meio ambiente do trabalho, ou até mesmo a garantia do exercício de direitos de ação coletiva, como a greve. Nesse último caso, o sindicato entrevistado entendeu que a luta pela conquista

${ }^{4}$ Pesquisa patrocinada pela Escola Superior do Ministério Público da União em parceria com o Centro de Estudos Direito e Sociedade - CEDES - do IUPERJ (Instituto Universitário de Pesquisas do Rio de Janeiro), tendo como coordenador o autor deste texto e como pesquisadores João Hilário Valentim e Bernardo Braga Pasqualette. 
de direitos cabia à organização profissional, e ao Ministério Público do Trabalho garantir que os instrumentos de ação coletiva previstos na Constituição pudessem ser livremente utilizados pelo ente sindical. Também foi verificada por alguns sindicatos a condição mais "positivista" da atuação da fiscalização do trabalho, e uma abertura maior do Ministério Público do Trabalho a questões que envolviam aplicações de princípios (cf. Carelli et al., 2007).

\section{CONCLUSÃO}

Assim, com campo e discursos próprios, vem o Ministério Público se somar às demais instituições de proteção ao sistema trabalhista, não com o condão de substituí-las, mas de cumprir o papel determinado ao "parquet" como um todo pela Constituição de 1988.

O Ministério Público do Trabalho, assim, aceitando a oportunidade concedida pela Constituição e pela legislação para a sua refundação, concentra agora grande parte das suas forças nessa nova missão: a defesa da sociedade pelo resguardo dos direitos fundamentais dos trabalhadores por meio da tutela coletiva, extrajudicial ou judicialmente, com a utilização de inquéritos civis e procedimentos investigatórios, firmando termos de compromisso de ajustamento de conduta, ou ajuizando ações civis públicas para a defesa da sociedade trabalhadora.

A Instituição passa, então, a traçar suas metas, todas elas voltadas para essa nova função de defensora da sociedade, em especial a trabalhadora (podendo coincidir ou não com os interesses dos trabalhadores, como vimos no estudo de casos). A coincidência de várias dessas metas com os direitos fundamentais dos trabalhadores, inclusive com os princípios indicados pela Organização Internacional do Trabalho como imprescindíveis e mínimos para a garantia da dignidade do trabalhador, demonstra que o "parquet" laboral está se posicionando em função diversa daquelas assumidas tanto pela Fisca- lização do Trabalho quanto pelas entidades sindicais, por não verificar o cumprimento da letra da lei trabalhista ou defender interesses dos trabalhadores com ações judiciais ou de negociação coletiva de condições de trabalho.

A tutela pelo Ministério Público não é, e não pretende ser, substitutiva àquela realizada pelas demais instituições, principalmente pelos sindicatos. Porém ela tem uma vantagem, que também pode ser aproveitada pelos sindicatos, quando ajuíza ações civis públicas ou mesmo ações individuais: a tutela trabalhista por meio de argumentação de Direitos Humanos tem o condão de desvincular a fruição dos direitos no trabalho das crises econômicas e do jogo de forças entre trabalhador e empregador. Assim, em conjuntura em que esse jogo pende para o empregador, a argumentação de Direitos Humanos restringe a possibilidade de o capital de aproveitar o momento para deslegitimar o Direito do Trabalho.

Assim, o Ministério Público do Trabalho, nessa conjunção de crise do Direito do Trabalho e refundação da instituição Ministério Público como órgão de defesa da sociedade, toma partido com força na defesa dos trabalhadores em seus direitos fundamentais.

(Recebido para publicação em 04 de janeiro de 2011) (Aceito em 11 de março de 2011)

\section{REFERÊNCIAS}

BADINTER, Robert; BREYER, Stephen. Initiative. Les entretiens de provence. Le juge dans la société contemporaine. Paris: Fayard, 2003.

CARDOSO, Adalberto; LAGE, Telma. As normas e os fatos: desenho e efetividade das instituições de regulação do mercado de trabalho no Brasil. Rio de Janeiro: FGV, 2007.

CARELLI, Rodrigo de Lacerda; VALENTIM, João Hilário; PASQUALETTE, Bernardo. Ministério Público do Trabalho como instância extrajudicial de solução de conflitos e os sindicatos. Rio de Janeiro: CEDES/IUPERJ, 2007.

CAPPELLETTI, Mauro. Juízes legisladores? Porto Alegre: Sergio Fabris, 1993.

FERRAJOLI, Luigi. Democracia y garantismo. Madrid: Trotta, 2008.

FRENCH, John D. Drowning in laws: labor law and brazilian 
political culture. Chapel Hill; London: University of North Carolina, 2004.

PAOLI, Maria Célia Pinheiro-Machado. Labor, law, and the State in Brazil, 1930-1950. 2004. (Phd Dissertation) Birkbeck College, University of London, 1988 apud FRENCH, John. Drowning in laws: labor law and brazilian political culture. Chapel Hill; London: University of North Carolina, 2004.

RADBRUCH, Gustav. Introducción a la ciencia del derecho.

Madrid: Biblioteca de la Revista de Derecho Privado, 1930.
SORJ, Bernardo. A democracia inesperada. Rio de Janeiro: Jorge Zahar, 1994.

SUPIOT, Alain. Homo Juridicus. Essai sur la fonction anthropologique du droit. Paris: Seuil, 2005.

WERNECK VIANNA et al. A judicialização da política e das relações sociais no Brasil. Rio de Janeiro: Revan, 1999. 


\section{LABOR PUBLIC ATTORNEYS ON PROTECTION OF LABOR RIGHTS}

\section{Rodrigo de Lacerda Carelli}

The Labor Public Attorneys, an institution that was before subordinate in the labor protective system, with the overhaul of the "parquet", from the 1980s, gained importance in the functional representation of workers, and the protection of fundamental rights at work. Thus, the text shows that, in time of crisis in Labour Law and its institutions, the Labor Public Attorneys enclose the role of society defender and acts in the protection of Labor Law, reinforcing it with the human rights argument. At the end, both the institution and the branch of law it strives to protect are strengthened.

KEYwoRds: Labor Public Attorneys, labor law, functional representation, human rights, labor.

\section{LE MINISTÈRE PUBILC POUR LA PROTECTION DES DROITS DU TRAVAIL}

\author{
Rodrigo de Lacerda Carelli
}

Le Ministère Public du Travail (le Parquet), institution antérieurement subordonnée au système de protection du travail, a pris de l'importance à partir des années 80 et grâce au remaniement du "parquet" quant à la représentation fonctionnelle des travailleurs pour la protection des droits fondamentaux au travail. Ce texte montre ainsi qu'en temps de crise pour les Droits du Travail et ses institutions, le Ministère Public du Travail assume un rôle de défenseur de la société et agit pour garantir les Droits du Travail en les renforçant avec les arguments des droits de l'homme. Au finale, autant l'institution que la branche du Droit qu'elle cherche à protéger s'en voient fortifiées.

Mots-clés: Ministère du Travail, droit du travail, représentation fonctionnelle, droits de l'homme, travail.

Rodrigo de Lacerda Carelli - Doutor em Ciências Sociais. Procurador do Ministério Público do Trabalho no Rio de Janeiro. Tem experiência na área de Sociologia e Direito, atuando principalmente nos seguintes temas: terceirização, precarização, direito do trabalho, cooperativa de trabalho e flexibilização. É autor dos livros: $O$ mundo do trabalho e os direitos fundamentais (Porto Alegre: Sergio Fabris, 2011); Formas atípicas de trabalho. (São Paulo: LTR, 2004); Terceirização e intermediação de mão-de-obra. (Rio de Janeiro: Renovar, 2002); Cooperativas de mão-de-obra: manual contra a fraude. (São Paulo: LTR, 2002) e vários artigos em periódicos (Boletim CEDES; Revista do Ministério Público do Trabalho; Revista de Direito Constitucional e do Trabalho; Revista de Direito do Trabalho). Integra o Núcleo de Pesquisa CEDES - Centro de Estudos Direito e Sociedade - IESP-UERJ. 